\title{
Hypoxia-Mediated Mechanisms Associated with Antiangiogenic Treatment Resistance in Glioblastomas
}

Sean Mahase, ${ }^{*}$ Rachel N. Rattenni, * Pieter Wesseling, ${ }^{\dagger \dagger}$ William Leenders, $^{\S}$ Clarissa Baldotto, ${ }^{\Uparrow}$ Rajan Jain, ${ }^{* *}$ and

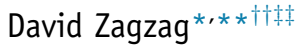

From the Microvascular and Molecular Neuro-Oncology Laboratory, * the Departments of Radiology," and Neurosurgery, ** the Division of Neuropathology ${ }^{\dagger \dagger}$ Department of Pathology, and the Laura and Isaac Perlmutter Cancer Center, ${ }^{\ddagger \ddagger}$ New York University School of Medicine, New York, New York; the Department of Pathology, ${ }^{\dagger}$ VU University Medical Center, Amsterdam, the Netherlands; the Department of Pathology, ${ }^{\ddagger}$ Princess Máxima Center for Pediatric Oncology and University Medical Center, Utrecht, the Netherlands; the Department of Pathology, ${ }^{\S}$ Radboud University Medical Center, Nijmegen, the Netherlands; and the Medical Oncology, "Instituto Nacionale de Cancer, Rio de Janeiro, Brazil

Accepted for publication

January 5, 2017.

Address correspondence to David Zagzag, M.D., Ph.D., New York University Langone Medical Center, 550 1st Ave., Medical Sciences Bldg. 521, New York, NY 10016. E-mail: david.zagzag@nyumc.org.

\begin{abstract}
Glioblastomas (GBMs) are malignant tumors characterized by their vascularity and invasive capabilities. Antiangiogenic therapy (AAT) is a treatment option that targets GBM-associated vasculature to mitigate the growth of GBMs. However, AAT demonstrates transient effects because many patients eventually develop resistance to this treatment. Several recent studies attempt to explain the molecular and biochemical basis of resistance to AAT in GBM patients. Experimental investigations suggest that the induction of extensive intratumoral hypoxia plays a key role in GBM escape from AAT. In this review, we examine AAT resistance in GBMs, with an emphasis on six potential hypoxia-mediated mechanisms: enhanced invasion and migration, including increased expression of matrix metalloproteinases and activation of the C-MET tyrosine kinase pathway; shifts in cellular metabolism, including up-regulation of hypoxia inducible factor- $1 \alpha$ 's downstream processes and the Warburg effect; induction of autophagy; augmentation of GBM stem cell self-renewal; possible implications of GBM-endothelial cell transdifferentiation; and vasoformative responses, including vasculogenesis, alternative angiogenic pathways, and vascular mimicry. Juxtaposing recent studies on well-established resistance pathways with that of emerging mechanisms highlights the overall complexity of GBM treatment resistance while also providing direction for further investigation. (Am J Pathol 2017, 187: 940-953; http://dx.doi.org/ 10.1016/j.ajpath.2017.01.010)
\end{abstract}

Glioblastomas (GBMs) are the most prevalent primary brain tumors. Even with a standard treatment entailing surgical resection, followed by concurrent radiation therapy (RT) and temozolomide (TMZ), the average survival for GBM patients is only 12 to 15 months. ${ }^{1}$ GBMs are classified as either primary GBMs, which develop de novo, tend to enlarge rapidly, and are usually not $I D H 1$ mutated, or as secondary GBMs, which slowly develop from low-grade astrocytomas, and are most often IDH1 mutated. Histologically, primary and secondary GBMs are identical, both possessing the defining characteristics of hypercellularity, cellular pleomorphism, mitotic figures, necrosis that may be surrounded by pseudopalisading cells, and extensive yet abnormal vasculature.

GBM cells initially associate along normal blood vessels to procure their oxygen and nutrient requirements for growth through diffusion. The rapidly proliferating GBM cells may compromise the integrity of the vessels they grow around, eventually leading to vascular collapse. The resulting reduced tumor perfusion initially kills a fraction of GBM cells in the vicinity, while selecting for cells that are

Supported by NIH/National Cancer Institute grant R21NS074055 (D.Z.). Disclosures: None declared. 
able to survive in the ensuing hypoxic environment. ${ }^{3}$ Alternatively, rapidly growing tumor cells may become localized too far from the most nearby vessel to maintain normoxia. Under reduced oxygen tensions, the remaining GBM cell cohort initiates the hypoxia-inducible factor (HIF)-1 pathway, endowing cells with the ability to adapt to hypoxic environments, among others, by inducing expression of vascular endothelial growth factor (VEGF)-A.

\section{Effects of Neovascularization}

The use of angiogenesis to overcome nutrient and oxygen limitations leads to exponential tumor growth. VEGF-A, expressed by hypoxic cancer cells, causes a loss of blood brain barrier (BBB) integrity, resulting from heterogeneity in basement membrane thickness and abnormal or absent endothelial cell (EC) and pericyte coverage. ${ }^{4-6}$ These irregular blood vessels are morphologically compromised and dysfunctional with large diameters, highly permeable walls, and tortuous, disorganized, and blind loops. ${ }^{7}$ Intratumoral blood flow is thus impeded, creating a heterogeneous tumor environment with respect to oxygenation and interstitial fluid pressure. ${ }^{5}$ Inconsistent intratumoral oxygenation leads to hypoxia, acidosis, and necrosis, whereas the increased hydrostatic pressure outside of the GBM vasculature promotes intratumoral edema, a major cause of morbidity for GBM patients. ${ }^{7}$

\section{VEGF}

The most thoroughly studied proangiogenic pathway is that initiated by the VEGF family of growth factors, whose members, structure, function, and regulation have been described previously. ${ }^{8}$ VEGF is produced by several GBM components, including tumor, stromal, and inflammatory cells, stimulating microvascular EC VEGF receptor (VEGFR) expression, and leading to EC proliferation, migration, survival, and tube formation. VEGF both dilates vessels and increases their permeability, potentially increasing tumor perfusion, but it may also increase interstitial pressure. ${ }^{5,9,10}$ In addition, VEGF can stimulate EC nitric oxide synthase expression, leading to production of nitric oxide, a gasotransmitter involved in a plethora of physiological pathways, including vasodilation. ${ }^{10}$ These abilities underlie VEGF's predominant role in forming the immature, dysfunctional vasculature, and impaired BBB that contributes to vasogenic edema.

\section{AAT}

\section{Rationale for Use}

Targeting angiogenesis is considered a promising method to halt angiogenesis-dependent tumor growth. Because angiogenesis plays a limited physiological role in adults, antiangiogenic therapy (AAT) should be tumor specific with limited adverse effects. Potential AAT interventions include the following: administering or overexpressing angiogenic inhibitors (eg, neutralizing antibodies against VEGF-A, or its receptor VEGFR2 via VEGFR2 kinase inhibitors), interfering with the functions of EC adhesion molecules and extracellular matrix components (eg, using RGD peptides, interfering with integrin-fibronectin interactions), and inhibiting production of proangiogenic factors.

Most antiangiogenic strategies historically concentrated on inhibiting binding of the VEGF ligand to its cognate receptor(s). Specifically inhibiting VEGFRs expressed on tumor microvascular ECs (TMVECs) is potentially therapeutically advantageous. Unlike neoplastic GBM cells, TMVECs can be accessed without bypassing the BBB. TMVECs are also thought to be genetically stable; therefore, there is less risk of developing therapeutic resistance. Utilizing this approach, a number of inhibitors are currently undergoing phase 2 or 3 clinical trials. This includes the tyrosine kinase inhibitor cediranib that targets all VEGF subtypes, platelet-derived growth factor (PDGF) receptor, and c-Kit, and the recombinant fusion protein, aflibercept (VEGF trap), which functions as a decoy VEGFR. Few have received Food and Drug Administration approval for GBM treatment, and none have proved to be an effective long-term treatment.

\section{BEV}

Bevacizumab (BEV; Avastin) is a humanized monoclonal antibody against the VEGF-A ligand that prevents VEGF interactions with VEGFR1 and VEGFR2. BEV was initially approved for combinatorial first-line therapy with chemotherapy in metastatic colorectal cancer, with subsequent approval for advanced non-small cell lung cancer and metastatic renal cell carcinoma, cervical cancer, and platinum-resistant ovarian cancer. ${ }^{11}$ Clinical trials using single-agent BEV in recurrent GBMs demonstrated radiologic response with decreased steroid dependence in a subset of patients. ${ }^{11}$ These findings, and the subsequent Food and Drug Administration approval, prompted the AVAglio and RTOG 0825 studies, which were phase 3, double-blinded, placebo-controlled trials to evaluate BEV in combination with RT and TMZ in patients with newly diagnosed GBM. Both trials failed to show improved overall survival (OS) in their respective BEV treatment arms. The AVAglio BEV study arm demonstrated a statistically significant improvement in progression-free survival (PFS) compared with the control group, whereas RTOG 0825 reported a nonsignificant improvement of PFS in the BEV cohort. ${ }^{4,12}$

Numerous trials consistently demonstrate an increased PFS not translating to improved OS. This may be partially attributed to BEV decreasing vessel permeability, affecting contrast enhancement-based assessments of treatment response (Figure 1). Most BEV-treated patients demonstrate transient benefits, but they inevitably progress, demonstrating an acquired therapeutic resistance to further treatments (Figure 2). ${ }^{13}$ Some propose that BEV's transient 

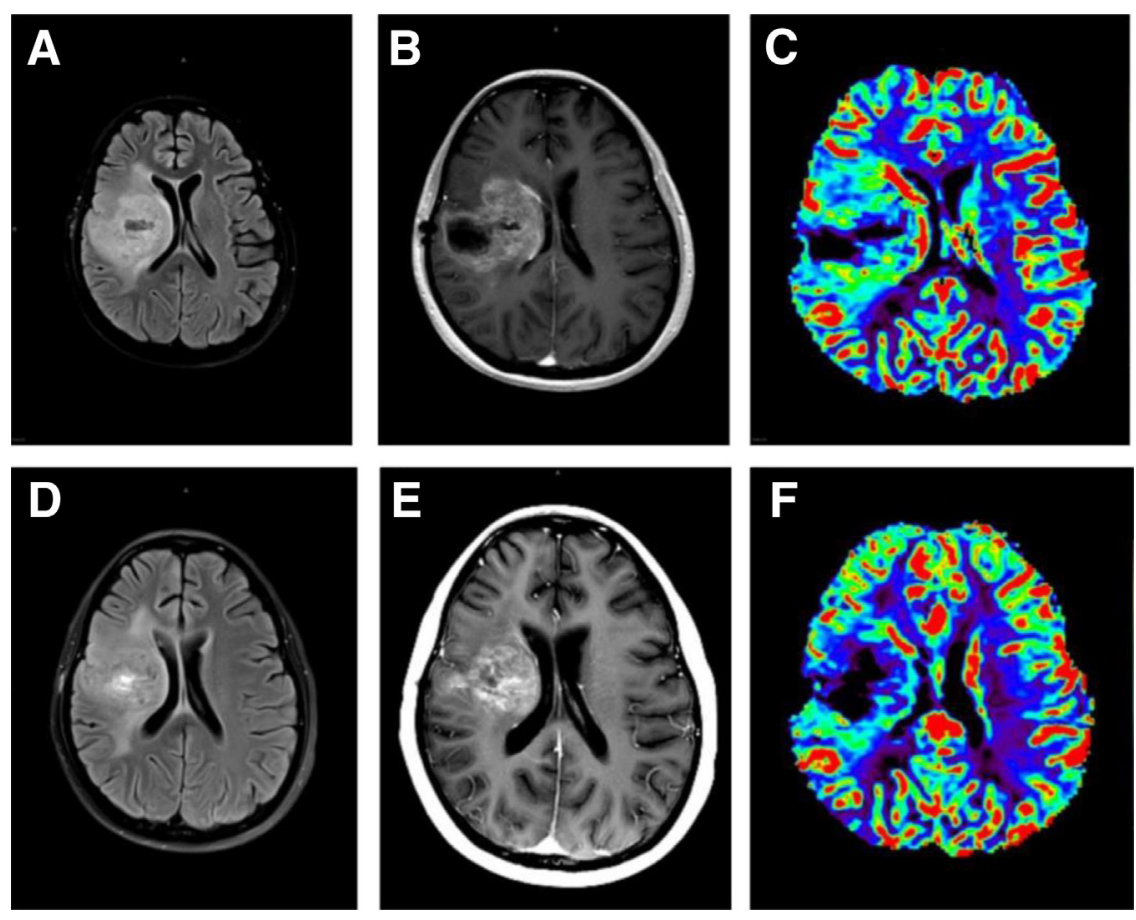

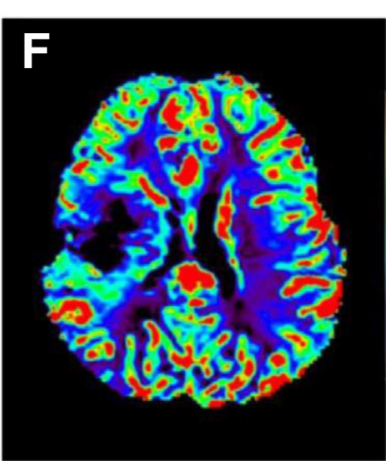

Figure 1 Twenty-two-year-old female, previously treated for an anaplastic astrocytoma at New York University Langone Medical Center, started on bevacizumab (BEV) 6 months after the initial diagnosis for a progressive recurrent tumor. Baseline imaging before BEV treatment: axial flair (A), axial view after contrast (B), and DSC T2* ${ }^{*}$ cerebral blood volume parametric maps (C) showing a large, recurrent, heterogeneously enhancing glioblastoma with surrounding edema and mass effect, as well as markedly increased blood volume. Four weeks after BEV treatment: axial flair (D), axial view after contrast (E), and dynamic susceptibility contrast (DSC) T2* cerebral blood volume parametric maps (F) showing slight improvement in the size and degree of enhancement of the large heterogenous tumor, with slight improvement in the swelling and edema. Remarkably, cerebral blood volume maps show reduction in tumor blood volume, suggestive of typical initial response seen with antiangiogenic therapy. effects can be ascribed to the prominent, often glomeruloid neovasculature in GBM being inherently too dysfunctional at diagnosis to prevent extensive necrosis. ${ }^{14}$ Moreover, because of the diffuse infiltrative growth pattern, diffuse glioma cells may be able to use the pre-existent and abundant cerebral microvasculature. ${ }^{14}$ In addition, there is increasing concern that BEV enhances the tumor's invasive phenotype in patients who initially demonstrate a treatment response (Table 1). ${ }^{13,15,16}$ Norden et al ${ }^{17}$ reported a significant increase in diffuse GBM recurrence in patients with a radiologic response to BEV therapy, suggesting BEV's anti-VEGF activity promotes an invasive phenotype. Narayana et $\mathrm{al}^{18}$ showed 50 of 61 patients demonstrating radiologic responses to $\mathrm{BEV}$ treatment eventually relapsed,
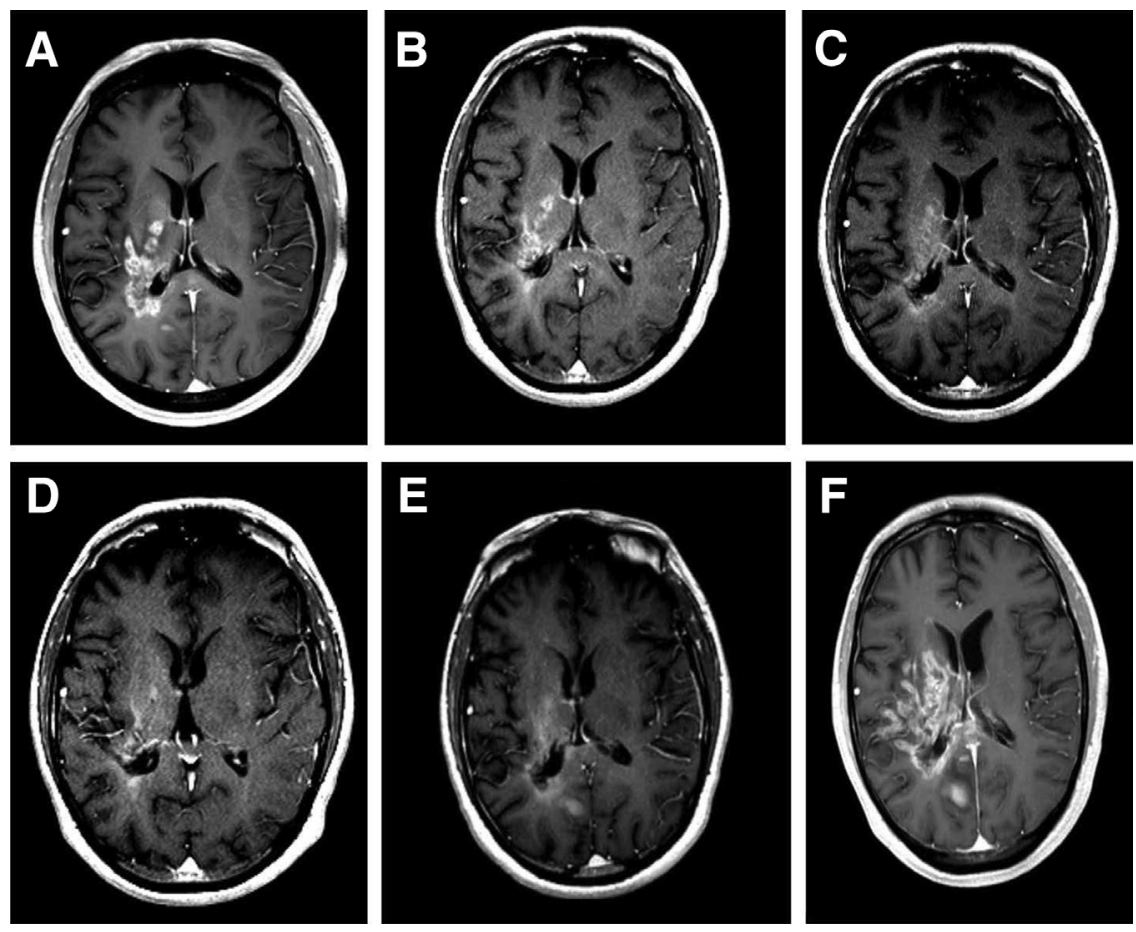

Figure 2 A series of T1-weighted images after contrast depict the clinical course of a 41-year-old man with a large recurrence of glioblastoma in the right cerebral hemisphere who received 17 administrations of bevacizumab (BEV) over 36 months. A: Baseline imaging before starting BEV shows heterogenous areas of enhancement. B-D: Six (B), 30 (C), and 38 (D) weeks of BEV therapy shows progressively decreasing size of the contrast-enhancing lesion with improvement in swelling and mass effect. E: Six weeks after stopping BEV the image shows recurrence of the enhancing lesion. F: Twelve weeks after stopping BEV the image shows dramatic increase in enhancement. The patient died 20 weeks after stopping BEV therapy because of progressive increase in size of the tumor. 
Table 1 GBM Clinical Studies Describing Recurrence Patterns after BEV Therapy

\begin{tabular}{|c|c|c|c|c|c|c|}
\hline Study & $\begin{array}{l}\text { Prospective } \\
\text { or retrospective }\end{array}$ & $\begin{array}{l}\text { Recurrent } \\
\text { or newly } \\
\text { diagnosed GBM }\end{array}$ & Treatment regimen & $\begin{array}{l}\text { Patients treated } \\
\text { with } \mathrm{BEV}, n\end{array}$ & $\begin{array}{l}\text { Recurrence rate } \\
\text { in BEV-treated } \\
\text { patients, } n(\%)\end{array}$ & $\begin{array}{l}\text { Development of } \\
\text { diffuse disease } \\
\text { in BEV-treated } \\
\text { patients, } n(\%)\end{array}$ \\
\hline $\begin{array}{l}\text { Iwamoto } \\
\text { et al, } 2009^{13}\end{array}$ & Retrospective & Recurrent & $\mathrm{BEV}+$ irinotecan $+\mathrm{RT}$ & 37 & $37(100)$ & $6(16)$ \\
\hline $\begin{array}{l}\text { Narayana } \\
\text { et al, } 2012^{15}\end{array}$ & Retrospective & $\begin{array}{c}\text { Newly diagnosed } \\
\text { and recurrent }\end{array}$ & $\mathrm{BEV}+\mathrm{TMZ} \pm \mathrm{RT}$ & $\begin{array}{l}\text { Total: } 162 \\
\text { Recurrent GBM: } 104 \\
\text { New GBM: } 58\end{array}$ & $105(64.8)$ & $\begin{array}{l}\text { Total: } 79 \text { (48.8) } \\
\text { Recurrent GBM: } \\
50 \text { (48.1) } \\
\text { New GBM: } 29(50)\end{array}$ \\
\hline $\begin{array}{l}\text { Narayana } \\
\text { et al, } 2012^{16}\end{array}$ & Prospective & Newly diagnosed & $B E V+T M Z+R T$ & 51 & $35(68.6)$ & $20(57.1)$ \\
\hline $\begin{array}{l}\text { Norden } \\
\quad \text { et al, } 2008^{17}\end{array}$ & Retrospective & Recurrent & $\begin{array}{l}\text { BEV + irinotecan, } \\
\text { carboplatin or } \\
\text { carmustine }\end{array}$ & 26 & $24(92.3)$ & $4(15)$ \\
\hline
\end{tabular}

BEV, bevacizumab; GBM, glioblastoma; RT, radiation therapy; TMZ, temozolomide.

with 15 presenting with relapsing, diffuse infiltrative disease. Biopsies after $\mathrm{BEV}$ treatment from six of these patients revealed a potential correlation between diffuse relapse and an invasive mesenchymal tumor phenotype. However, a recent publication by Wick et al $^{19}$ evaluating responses of $\mathrm{BEV}$ or placebo plus TMZ/RT suggests that, although patients with invasive GBMs before treatment had worse OS than patients with nondiffuse tumors, OS was not affected by developing an invasive phenotype after BEV treatment. Our presently evolving understanding of BEV's clinical effects, as evidenced by the aforementioned trials, may be furthered by improving radiologic assessments and through our understanding of GBM's heterogeneous nature.

BEV-Mediated Effects on GBM Vasculature and Induction of a Hypoxic Environment

Keunen et $\mathrm{al}^{20}$ demonstrated that BEV-treated xenografts exhibit decreased tumor progression and T1-weighted contrast enhancement compared with controls, consistent with findings in patients treated with BEV. Dynamic contrast-enhanced magnetic resonance imaging (MRI) used in conjunction with pharmokinetic models showed that BEV-treated xenografts possess decreased vascular permeability and reduced blood flow per unit tissue. BEV-mediated normalization of GBM vasculature, denoted by decreased vessel permeability, a reduction in large and medium-sized vessels, and sparing of smaller caliber vessels, did not translate to functional vasculature normalization, as indicated by their reduced vessel perfusion. ${ }^{20}$ Hamans et $\mathrm{al}^{21}$ used multivoxel magnetic resonance spectroscopy with histologic and immunohistochemistry analyses to demonstrate increased hypoxia and lactate levels in compact, rapidly growing tumor areas within orthotopic diffuse-infiltrative GBM xenografts after AAT. Importantly, diffuse infiltrative tumors treated with BEV or cabozantinib (combined VEGFR2/c-MET kinase inhibitor) did not demonstrate increased hypoxia or lactate concentrations. They ascribe these findings to AAT predominantly affecting and rapidly decreasing perfusion to angiogenesis-dependent compact tumor regions that were already previously outgrowing their blood supply. ${ }^{21}$ These findings contrast prior notions that AAT will normalize aberrant GBM vasculature and restore perfusion, thereby improving chemotherapy delivery, tumor oxygenation, and RT efficacy (Figure 3). ${ }^{21-23}$ Thus, AAT-mediated reduction in perfusion to only rapidly growing, angiogenesis-dependent tumor regions may potentially account for observations of BEV-treated patients developing resistance to RT and chemotherapeutic regimens. Alternatively, BEV may transiently normalize vessel function and restore perfusion for a limited time period, but concomitantly it may hamper delivery of therapeutics from the circulation to the tumor cells, resulting in therapeutic resistance. Future studies may elucidate whether sequential treatment with RT/ chemotherapy and angiogenesis inhibitors can optimize AAT treatment protocols for GBMs.

With the use of sequential biopsies from patients who initially responded to BEV treatment, Iwamoto et $\mathrm{al}^{13}$ demonstrated marked increases in HIF- $1 \alpha$ and carbonic anhydrase IX (CA9) at the time of BEV failure compared with tumor tissue biopsied before BEV exposure. de Groot et $\mathrm{al}^{23}$ subsequently compared tumor specimens from patients who became resistant to BEV therapy with a U87 xenograft tumor model induced to switch to an infiltrative phenotype after BEV treatment. Both patient and xenograft tumors treated with BEV demonstrated less vascular proliferation, increased CA9 staining, prominent invasive borders, and increased expression of matrix metalloproteinase (MMP) 2 and insulin-like growth factor binding protein 2, which are implicated as molecular mediators of tumor invasion. ${ }^{23}$ Several studies using mice models showed BEV-treated tumor sections possessed increased 


\section{Normal Vasculature}

A

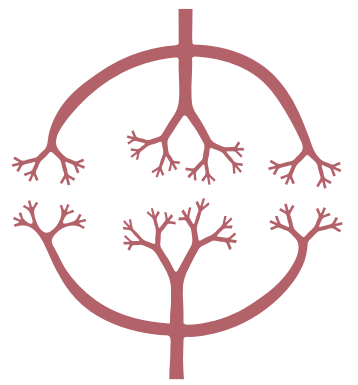

\section{GBM Vasculature}

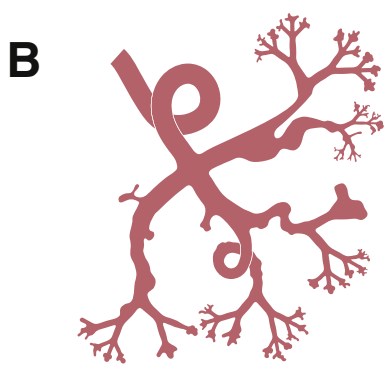

Antiangiogenic Therapy

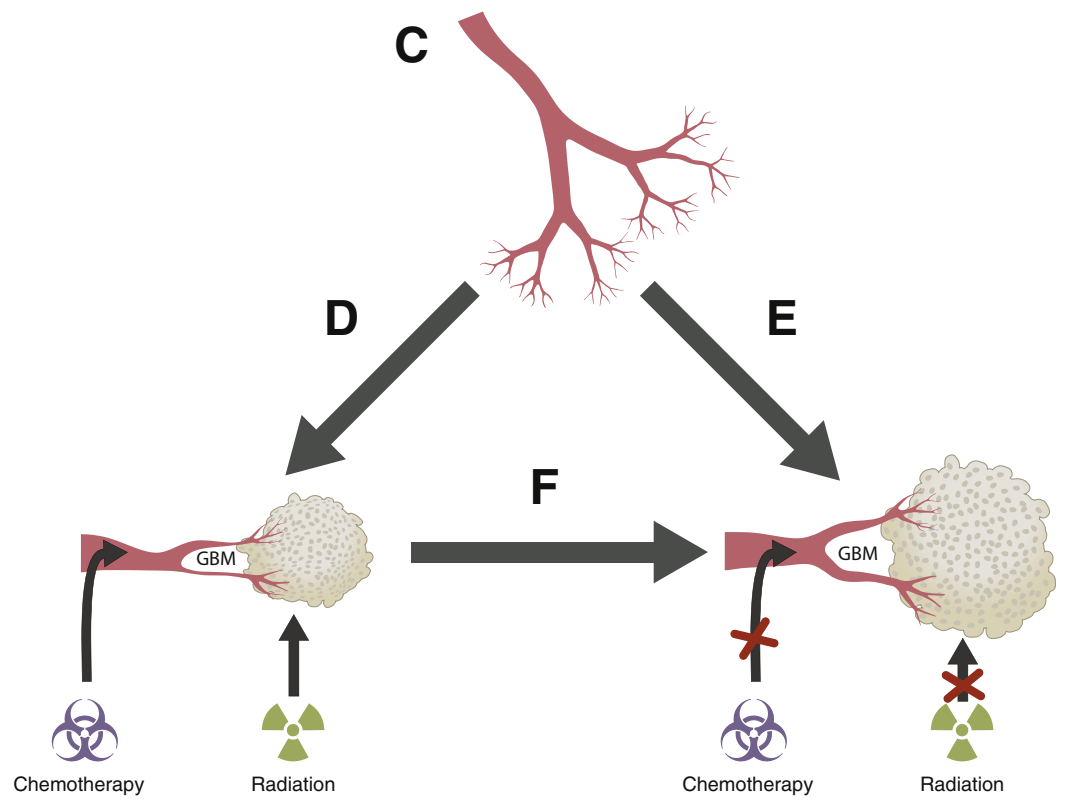

Figure 3 Proposed effect of antiangiogenic therapy on glioblastoma (GBM) vasculature. A: Normal brain vasculature. B: GBM vasculature: aberrant vascular architecture with dilated, highly permeable blood vessels and multiple blind loops. C: After BEV treatment: BEVmediated normalization of glioma vasculature is denoted by decreased vessel permeability and a reduced number of large- and mid-sized vessels. D: Theory 1 : antiVEGF treatment restores perfusion, promoting improved chemotherapy delivery and radiation therapy efficacy. E: Theory 2: structural changes entailing vessel normalization do not result in completely functional or normal vasculature. F: Theory 3: At some point after treatment, the anti-VEGF-induced vasculature normalization is eventually lost for reasons still to be (further) elucidated, and the tumor becomes resistant to additional antiangiogenic therapy. BEV, bevacizumab; VEGF, vascular endothelial growth factor. tissue hypoxia but reduced GBM cell proliferation, microvascular proliferation, and necrosis in the tumor core, suggesting tumor growth persisted in the absence of oxygen. . $^{20,24,25}$

Collectively, these experimental studies suggest that BEV treatment normalizes intratumoral vasculature (Table 2), but it decreases perfusion in rapidly growing tumor areas with a pre-existing blood supply shortage, creating a hypoxic tumor environment while promoting GBM cell survival and migration. $^{20,21,23-25}$

\section{Hypoxia-Mediated Mechanisms of Antiangiogenic Therapy Treatment Resistance}

Increased intratumoral hypoxia has been correlated with tumor aggressiveness, apoptotic resistance, and poor prognosis. ${ }^{23,26}$ Experimental studies demonstrate that hypoxia fosters resistance to RT through depleting free radicals and mitigating radiation-induced DNA damage. ${ }^{27}$ Intratumoral hypoxia also mitigates chemotherapeutic efficacy, with abnormal vasculature impeding drug delivery, and decreased proliferation conferring resistance to agents that target rapidly dividing cells. ${ }^{5,28}$ Here, we review the following six possible mechanisms of AAT resistance: i) enhanced invasion and migration, ii) shifts in cellular metabolism, iii) changes in autophagy regulation, iv) GBM stem cells (GSCs), v) GBM-EC transdifferentiation, and vi) vasoformative responses (Figure 4).

\section{Enhanced Invasion and Migration}

A microarray and immunohistochemistry analysis of BEV-resistant human GBMs by DeLay et $\mathrm{al}^{29}$ revealed two different GBM subtypes with distinct responses to AAT. The first subtype exhibits MRI enhancement; expression of mitogen-activated protein kinases, neural cell adhesion molecule-1, and aquaporin 4; unchanged oxygenation and vascularity; and increased proliferation. In contrast, the second GBM phenotype demonstrated minimal MRI enhancement, less vascularity, increased hypoxia; increased expression of HIF- $1 \alpha$, integrin $\alpha 5$, laminin, fibronectin 1 , CXCL12, and PDGF- $\beta$; unchanged proliferation; and 
Table 2 Translational Studies Supporting BEV-Induced GBM Hypoxia and Enhanced Invasive Phenotype

\begin{tabular}{|c|c|c|c|c|c|c|}
\hline Study & Animal model & Tumor material & $\begin{array}{l}\text { Time between } \\
\text { implanting tumor and } \\
\text { starting BEV }\end{array}$ & BEV regimen & Controls & $\begin{array}{l}\text { Time between } \\
\text { initiating BEV and } \\
\text { sacrificing mice }\end{array}$ \\
\hline $\begin{array}{l}\text { Keunen } \\
\text { et al, } 2011^{20}\end{array}$ & $\begin{array}{l}\text { Athymic nude } \\
\text { rats }\end{array}$ & $\begin{array}{l}\text { Standardized pool of } \\
\text { GBM-derived } \\
\text { spheroids obtained } \\
\text { from one patient } \\
\text { and expanded } \\
\text { through serial } \\
\text { transplantation in } \\
\text { nude rats }\end{array}$ & 3 weeks & $\begin{array}{l}10 \mathrm{mg} / \mathrm{kg} \mathrm{i.v.} \\
\text { weekly }\end{array}$ & Yes & 3 weeks \\
\hline $\begin{array}{l}\text { Hamans } \\
\text { et al, } 2013^{21}\end{array}$ & $\begin{array}{c}\text { Athymic BALB/c } \\
\text { nu/nu mice }\end{array}$ & E98 or E473 GBM cells & $\begin{array}{l}\text { When signs of tumor } \\
\text { growth became } \\
\text { apparent: presence } \\
\text { of edema on } \mathrm{T}_{2^{-}} \\
\text {weighted } \mathrm{MRI}\end{array}$ & $\begin{array}{l}5 \mathrm{mg} / \mathrm{kg} \text { i.p. } \\
\text { twice weekly }\end{array}$ & Yes & $\begin{array}{l}\text { Signs of clinical } \\
\text { deterioration: } \\
>15 \% \text { weight loss } \\
\text { in } 2 \text { days; severe } \\
\text { neurologic } \\
\text { abnormalities }\end{array}$ \\
\hline $\begin{array}{l}\text { Kumar } \\
\text { et al, } 2013^{24}\end{array}$ & $\begin{array}{l}\text { BALB/c SCID or } \\
\text { athymic nude } \\
\text { mice }\end{array}$ & $\begin{array}{l}\text { U87-MG or U118-MG } \\
\text { cells }\end{array}$ & $\begin{array}{l}\text { Tumor volume } \\
\text { reached } 150 \mathrm{~mm}^{3}\end{array}$ & $\begin{array}{l}10 \mathrm{mg} / \mathrm{kg} \text { i.p. } \\
\text { every } 3 \text { days }\end{array}$ & Yes & $\begin{array}{l}\text { Until tumors reached } \\
600-800 \mathrm{~mm}^{3}\end{array}$ \\
\hline $\begin{array}{l}\text { Rapisarda } \\
\text { et al, } 2009^{25}\end{array}$ & $\begin{array}{l}\text { Athymic nude } \\
\text { mice }\end{array}$ & U251-HRE cells & $\begin{array}{l}\text { Tumors reached } \\
\sim 175 \mathrm{mg}\end{array}$ & $\begin{array}{l}5 \mathrm{mg} / \mathrm{kg} \text {, every } \\
3 \text { days } \times 4 \text { times }\end{array}$ & Yes & Day 29 of treatment \\
\hline
\end{tabular}

BALB, Bagg albino; BEV, bevacizumab; GBM, glioblastoma; MRI, magnetic resonance imaging; SCID, severe combined immunodeficiency.

increased invasion. ${ }^{29}$ It is possible that these two distinct transcriptional phenotypes depend on the ability of AAT to induce intratumoral hypoxia. Increased proliferation is preferred under normoxic conditions, whereas AAT-induced vessel regression and hypoxia promote GBM survival through enhancing invasion while restricting local proliferation.

As a group, MMPs play roles in degrading extracellular matrix proteins, cleaving protein substrates, including growth factors, chemokines, and other MMPs, and in controlling cell proliferation. VEGF can induce MMPs to modify the basement membrane, promoting EC migration. MMP-9 is involved in normalizing aberrant tumor vasculature through collagen degradation during AAT. ${ }^{30}$ de Groot et $\mathrm{al}^{23}$ showed that regional hypoxia and increased MMP-2 expression in U87 xenografts after BEV treatment induces an invasive phenotype similar to biopsy specimens from patients with nonenhancing infiltrating BEV-resistant GBMs. These results suggest GBM cells escape regional hypoxia after prolonged BEV treatment through up-regulating MMPs, enhancing invasion into the surrounding brain parenchyma.

The c-MET tyrosine kinase receptor and its ligand, scatter factor/hepatocyte growth factor (SF/HGF), are strongly overexpressed in a subset of GBMs. Cerebrospinal fluid $\mathrm{SF} / \mathrm{HGF}$ levels and intratumoral HGF/SF and c-MET expression are associated with poor prognosis. ${ }^{31}$ Overexpression of VEGFR coreceptors, neuropilin-1 and -2, on ECs in GBMs augment angiogenesis and growth through potentiating c-MET signaling pathway activity. ${ }^{32}$ The
c-MET promoter contains a HIF-1 binding site and is up-regulated in hypoxic glioma cells and in tumors of BEV-resistant patients. ${ }^{33}$ Furthermore, there were increased levels of phosphorylated (activated) c-MET, c-METs' downstream mediators, focal adhesion kinase (FAK) and STAT3, and CA9. ${ }^{34}$ Similar findings were observed in BEV-resistant U87 GBM cell line-derived xenografts that also demonstrated discontinuous invasive patterns. Transducing BEV-resistant xenografts with c-MET shRNA reduced tumor cell survival under hypoxic conditions, reduced GBM cell invasiveness, and restored therapeutic responsiveness to $\mathrm{BEV}$, suggesting hypoxia, c-MET up-regulation, and phosphorylation of c-METs' downstream effectors may be specific to a BEV-resistant phenotype. ${ }^{35}$ $\mathrm{Lu}$ et $\mathrm{al}^{36}$ demonstrated VEGF knockout (KO) GBM cells intracranially implanted in mice were nonangiogenic, with increased invasiveness marked by disseminated tumor cell clusters within the brain parenchyma. These clusters also expressed higher levels of phosphorylated c-MET compared with wild-type GBM, despite both groups expressing similar levels of c-MET, suggesting a negative regulation of MET activation by the VEGF-VEGFR2 axis. Similar observations were made comparing phosphorylated c-MET expression in patient GBM biopsies before BEV treatment and after relapse, suggesting VEGF inhibition promotes c-MET activation without increasing expression. ${ }^{36}$ VEGF KOshMET tumors displayed decreased distant metastases, proliferation, and vascular density, resulting in increased survival compared with wild-type GBM and VEGF KO 

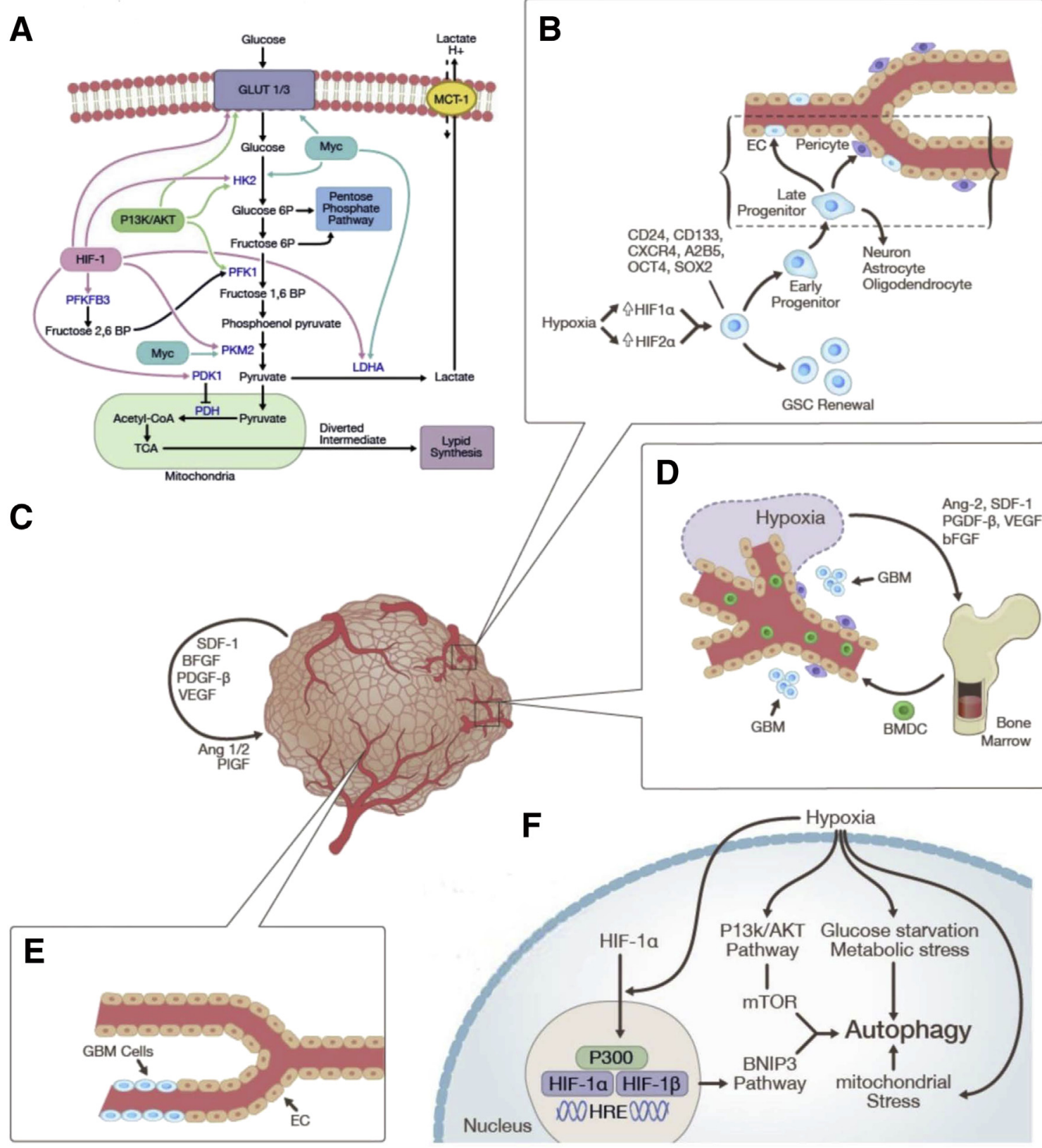

Figure 4 Hypoxia-mediated mechanisms of resistance to therapeutic modalities (see Figure 2 and Tables 1 and 2 for illustrations of enhanced migration and invasion): shifts in cellular metabolism (A); GSCs and GBM-EC transdifferentiation (B); vasoformative responses entailing alternate angiogenic pathways (C), vasculogenesis (D), and vascular mimicry (E); and autophagy (F). Ang, angiopoietin; bFGF, basic fibroblast growth factor; BMDC, bone marrow-derived cell; BNIP, Bcl/E1B 19kD interacting protein; BP, bisphosphate; CoA, coenzyme A; EC, endothelial cell; GBM, glioblastoma; GLUT, glucose transporter; GSC, glioblastoma stem cell; HIF, hypoxia-inducible factor; HK2, hexokinase-2; HRE, hypoxia-response element; LDHA, lactate dehydrogenase A; MCT, monocarboxylate transporter; mTOR, mechanistic target of rapamycin; OCT4, octamer-binding transcription factor 4; $\mathrm{P}$, phosphate; PDGF, platelet-derived growth factor; PDH, pyruvate dehydrogenase; PDK, pyruvate dehydrogenase kinase; PFKFB3, 6-phosphofructo-2-kinase/fructose-2,6-biphosphatase 3; PI3K, phosphinositol-3-kinase; PKM2, pyruvate kinase muscle isozyme M2; PIGF, placental growth factor; SDF, stromal cell-derived factor; Sox2, sex determining region Y-box 2; TCA, tricarboxylic acid; VEGF, vascular endothelial growth factor.

tumor mice. ${ }^{36}$ With the use of E98 cells, Navis et $\mathrm{al}^{34}$ reported that cabozantinib inhibited c-MET phosphorylation, growth, and single-cell migration of E98 GBM cells in vitro, and increased OS in orthotopic E98 xenografts. In agreement with Hamans et al, ${ }^{21}$ cabozantinib decreased angiogenesis, promoted vascular normalization, and induced hypoxia in rapidly growing tumor regions while having less impact on diffusely infiltrative tumor regions. ${ }^{34}$ Cabozantinib's inability to completely inhibit c-MET in vivo may be secondary to it also restoring BBB function, thereby reducing drug delivery. ${ }^{34}$ VEGF-mediated inhibition of cMET can only be operational in a small subset of gliomas, in which cancer cells coexpress MET and VEGFR2. Although these and other studies implicate the c-MET 
pathway in cell migration, invasion, survival, and proliferation, thus advocating its utility as a therapeutic target, it is likely that because of GBM's heterogeneity, only a fraction of tumors will respond to c-MET inhibition.

A multicenter phase 2, single-agent study of AMG 102 (rilotumumab), a human monoclonal antibody against SF/HGF, in patients with recurrent GBM reported median OS of 6.5 months and 5.4 months in the $10-\mathrm{mg} / \mathrm{kg}$ and $20-\mathrm{mg} / \mathrm{kg}$ AMG 102 cohorts, respectively, with a PFS of 4.1 weeks and 4.3 weeks, respectively. No significant differences in PFS were observed between BEV-naive patients and patients who received prior BEV treatment. ${ }^{37}$ AMG 102 may prove effective when used as part of combination therapy or used as a preventive measure to mitigate the initiation of c-MET-mediated invasion.

\section{Shifts in Cellular Metabolism}

The complex interactions between various environmental stimuli, gene expression regulation, and the activation of metabolic pathways induced by hypoxia are currently being studied to identify potential therapeutic targets. The metabolic reprogramming of astrocytes undergoing neoplastic transformation is also being examined because it may also contribute to antineoplastic treatment resistance.

HIF- $1 \alpha$ enables GBM cell survival under hypoxic conditions through enhanced expression of numerous genes involved in proliferation, migration, and regulation of oxygen use; regional $\mathrm{pH}$; glucose consumption; and ATP production. ${ }^{38,39}$ Glucose uptake is increased through enhanced transcription of genes encoding glucose transporters. Although normal brain tissue primarily expresses hexokinase-1 to produce glucose-6-phosphate, glioma cells in perinecrotic areas aberrantly express hexokinase-2 (HK2), the first enzyme in the Embden-Meyerhoff/ glycolytic pathway, which is involved in shuttling metabolites through the mitochondrial intermembrane space. Exogenous HK2 expression in GBM cells is associated with increased proliferation and therapeutic resistance, whereas HK2 inhibition mitigates aerobic glycolysis, induces oxidative phosphorylation, and promotes apoptosis and invasion. ${ }^{40}$ HIF- $1 \alpha$ also up-regulates pyruvate dehydrogenase kinase (PDK)1, which deactivates pyruvate dehydrogenase, preventing pyruvate dehydrogenase-mediated pyruvate conversion to acetyl-coenzyme $\mathrm{A}$ and its subsequent entry into the tricarboxylic acid cycle. ${ }^{39}$ Michelakis et $\mathrm{al}^{41}$ treated three patients with recurrent GBM and two newly diagnosed GBM patients with the PDK inhibitor dichloroacetate. Three patients demonstrated radiologic evidence of tumor regression, and four patients were clinically stable 15 months after treatment. ${ }^{41}$

HIF-1 $\alpha$ 's downstream effects converge with other metabolic pathways. The phosphinositol-3-kinase (PI3K)/ Akt pathway is hyperactive in most GBM cells that overexpress membrane tyrosine kinases such as MET, endothelial growth factor receptor (EGFR), or PDGF receptor; plays crucial roles in aerobic and anaerobic glycolysis and lactate production; regulates cell surface glucose transporter expression; and enhances HK2 and phosphofructokinase 1 activity. ${ }^{40}$ The PI3K/Akt pathway shuttles glucose to biosynthetic pathways to produce fatty acids, cholesterol, and isoprenoids that all use acetylcoenzyme $\mathrm{A}{ }^{42} \mathrm{PI} 3 \mathrm{~K}$ pathway inhibition reduces glucose use and is correlated with tumor regression. ${ }^{41}$ Cells that depend on the Akt pathway primarily use aerobic glycolysis and undergo apoptosis when deprived of glucose. Myc also controls genes involved in cell cycle regulation, mitochondrial functions, and apoptosis, contributing to the glycolytic switch by up-regulating phosphofructokinase 1 , HK2, lactate dehydrogenase A, and glucose transporter. ${ }^{40}$ Myc promotes mitochondrial deamination of glutamine to glutamate, and reducing glutamine in Myc-regulated cells induces apoptosis. ${ }^{42}$

The Warburg effect is a hallmark of many malignancies whereby cells preferentially use glycolysis over oxidative phosphorylation, regardless of oxygen availability, by attenuating mitochondrial activity and increasing glucose uptake and lactic acid formation. ${ }^{42,43}$ This seemingly inefficient method of generating ATP endows rapidly dividing GBM cells with immunity to fluctuating oxygen tensions. ${ }^{39}$ Glucose metabolism is redirected to producing cellular building blocks, such as amino acids and nucleosides, needed to support their rapid proliferation rates. ${ }^{43}$ In BEVtreated tumors, magnetic resonance spectroscopy revealed focally increased concentrations of lactate, alanine, choline, myo-inositol creatine, taurine, and mobile lipids, which are associated with tissue hypoxia. In addition, hypoxiamediated HIF- $1 \alpha$ expression regulates the expression of genes encoding enzymes involved in the glucose metabolism to glycogen and lactate, including lactate dehydrogenase A, and monocarboxylate transporter 4, which facilitates lactate extrusion from cancer cells. ${ }^{20,39}$ Excess lactate is shuttled to surrounding cells in normoxic regions via diffusion in a paracrine manner. ${ }^{44}$ These cells express monocarboxylate transporter 1 and LDH-B, enabling lactate uptake, and either subsequent conversion to pyruvate to be used in oxidative phosphorylation, storage as high-energy metabolites, or acting as a substrate in other metabolic processes. ${ }^{39,44}$ Inhibiting monocarboxylate transporter 1 with $\alpha$-cyano-4-hydroxycinnamate in a mice tumor model promoted glucose use over lactate, depleting glucose reserves and resulting in hypoxic tumor cell death. ${ }^{45}$

These hypoxia-mediated metabolic alterations granting enhanced cell survival inspired diverse therapeutic approaches that are currently under investigation. Rapisarda et $\mathrm{al}^{25}$ showed that treating U251-HRE xenografts with $\mathrm{BEV}$ and topotecan, a topoisomerase I inhibitor that also inhibits HIF- $1 \alpha$ translation, significantly increased apoptosis and reduced cellular proliferation and tumor growth compared with controls, and compared with BEV or topotecan monotherapy. From evidence suggesting methylene blue (MB) affects brain metabolism, possesses 
neuroprotective abilities, and modulates mitochondrial functions, Poteet et $\mathrm{al}^{46}$ demonstrated that MB treatments as low as $1 \mu \mathrm{mol} / \mathrm{L}$ increased oxygen consumption and ATP levels, and decreased lactate production and proliferation of U87 GBM cell lines. MB inhibits cyclin A2 and cyclin B1, suggesting $\mathrm{MB}$ may have an additive therapeutic effect with TMZ, which also functions as a cell cycle inhibitor. ${ }^{46}$ However, a MB-treated human xenograft model failed to show any therapeutic response, which may be due to an inability to establish and maintain therapeutic MB concentrations. ${ }^{46}$ Velpula et $\mathrm{al}^{47}$ showed that PDK1 and EGFR colocalize in the mitochondrial matrix and that their expression increases in parallel with HIF- $1 \alpha$ expression. After treatment with si-PDK1, sh-EGFR, or dichloroacetate, U251 and 5310 cells shifted to oxidative metabolism, produced less lactate, and exhibited increased apoptosis and decreased proliferation. ${ }^{47}$

\section{Changes in Autophagy Regulation}

Necrosis, apoptosis, and autophagy are implicated as potential mediators of neoplastic cell death in hypoxic environments. $^{48}$ Autophagy, a lysosomal degradation pathway involved in normal cellular functioning, is historically characterized as a cellular survival response. ${ }^{49}$ However, studies suggest that under specific conditions it can act as a mechanism of programed cell death independent of apoptosis. ${ }^{50}$ Cancer cells may inhibit autophagic cell death through inducing the PI3K/AKT pathway or via growth factors and angiogenic molecules commonly up-regulated in hypoxic environments. ${ }^{51-54}$

$\mathrm{Bcl} / \mathrm{E} 1 \mathrm{~B} 19-\mathrm{kD}$ interacting protein (BNIP3) is a downstream mediator of HIF- $1 \alpha$ up-regulated under hypoxic conditions and is involved in arsenic trioside- and ceramide-induced autophagy in GBM cells..$^{53,55,56}$ Azad et $\mathrm{al}^{57}$ demonstrated that hypoxic U87 cells also had increased production of lysosomes and autophagolysosomes. Inhibiting both apoptosis (using caspase inhibitor z-VAD-fmk) and autophagy (using 3-methyladenine) showed hypoxic cell death is primarily autophagy mediated. Hypoxic U87 cells had elevated levels of BNIP3, correlating with increased cell death that could be inhibited using 3-methyladenine or siRNA-mediated BNIP3 knockdown. ${ }^{57}$ $\mathrm{Hu}$ et $\mathrm{al}^{32}$ reported that hypoxia induces autophagyassociated protein changes in GBM cells lines, including increased turnover of protein light chain 3 and p62 (a mediator of ubiquitinated protein degradation), and up-regulation of BNIP3. Comparing six pretreatment GBMs with matched BEV-resistant GBMs of the same patients revealed that the periphery of necrotic areas stained positive for BNIP3, correlating with the greater hypoxia seen after $\mathrm{BEV}$ failure. ${ }^{32}$ The in vitro early autophagy inhibitor 3-methyladenine and late autophagy inhibitor BafA1 disrupted hypoxia-induced GBM autophagy and increased apoptosis-mediated GBM cell death. ${ }^{32}$ Chloroquine (a Food and Drug Administration-approved late autophagy inhibitor) inhibited autophagy in GBM cells and decreased the viability of U87 under hypoxia without affecting BNIP3 expression, suggesting it exerts its effect downstream of BNIP3. ${ }^{32}$ Finally, combined BEV and chloroquine therapy inhibited tumor growth in a prolonged and significant manner. ${ }^{32}$

Autophagy is implicated in GBM resistance to TMZ and RT. Chen et $\mathrm{al}^{58}$ reported that high expression of vesicleassociated membrane protein 8 (VAMP8), involved in exocytosis and autophagy, is an independent negative prognostic factor for GBM patients. VAMP8 overexpression significantly stimulated GBM cell proliferation. GBM progenitor cells overexpressing VAMP8 had increased viability after treatment with TMZ, whereas antagonizing VAMP8 conferred hypersensitivity to TMZ. ${ }^{58}$ Overexpression of four autophagy proteins (VPS34, Beclin1, autophagy protein 5, and light chain 3) correlated with VAMP8 overexpression, and VAMP8-mediated TMZ resistance was abrogated after autophagy protein 5 or syntaxin-17 deletion. ${ }^{58}$ Palumbo et $\mathrm{al}^{59}$ demonstrated autophagy inhibition in irradiated and EGFR-silenced cells resulted in a general reduction of radio-sensitivity compared with the corresponding nontransfected samples, along with impaired proliferation and cell migration. Overall, these results suggest hypoxia preferentially induces autophagic cell death over apoptosis, and targeting autophagy inducers could promote GBM cell death. Although creating a therapeutic regimen targeting autophagy in combination with existing AAT in a given time interval may prove promising, it is clear that the complex regulatory mechanisms and upstream mediators of autophagy in the context of various cellular and microenvironmental cues warrant further elucidation.

\section{GSCs}

Evidence is mounting to support the role of GSCs, or of stem-like GBM cells, in GBM pathogenesis and treatment failure. Several studies delineate regional hypoxia's influence of GSC regulation, promoting targeting hypoxiainduced mediators to potentially circumvent GSC-mediated therapeutic resistance.

GSCs are thought to exist within specific anatomic and functional niches within GBMs, maintaining tumor mass through self-renewal and continual proliferation, with the ability to acquire both neuronal and glial characteristics. ${ }^{32,60}$ There is controversy with respect to GSC origins, cellular markers, and relative proportions within GBMs. Mounting evidence suggests GSCs differ from conventional SCs in their relative numbers, proliferative rate, marker expression, and genetic alterations. ${ }^{61}$ Normal SCs are found in specific anatomic and functional niches required for potentiating their self-renewal and proliferative abilities. ${ }^{62}$ GSCs are reported to be similarly found within a perivascular niche that establishes a relation between GSCs and the tumor vasculature. ${ }^{63,64}$ GSCs may potentially stimulate 
angiogenesis through various means, including increased VEGF production and paracrine interactions with neighboring cells. ${ }^{61}$

GSCs may also potentially exist in hypoxic niches that form in the tumor core and after AAT, using HIF-dependent functions to control their differentiation. ${ }^{62,65}$ Hypoxia increases the neural SC population expressing CD133 (prominin-1) within GBMs and leads to increased selfrenewal and proliferation of $\mathrm{CD}_{13} 3^{+}$cells in neurosphere cultures derived from human GBMs. ${ }^{66} \mathrm{CD} 133^{+}$cells in hypoxic environments retain a diverse differentiation potential and strongly express SC markers Oct4 and Sox2, targets of the Notch pathway, and oncogenes such as ZNF217, consistent with an enhancement of SC-like properties. ${ }^{67-69}$

Hypoxia promotes CD133 ${ }^{+}$GSC self-renewal through a HIF-1 $\alpha$-dependent mechanism associated with increased expression of CXCR4 (implicated in migration and invasion), A2B5 (cancer SC and glial progenitor marker), CD24 (involved in neural cell differentiation), and tissue inhibitor of metalloproteinase-1 and O6-methylguanine-DNA methyltransferase (chemoresistance). This response may be further modulated through interactions with the PI3K/Akt and extracellular signal-regulated kinase 1 and 2 pathways. ${ }^{65,70}$

Although HIF- $1 \alpha$ is present in both SCs and non-SCs, HIF- $2 \alpha$ is only significantly expressed in GSCs. ${ }^{68,71}$ HIF- $2 \alpha$ has unique genetic targets, has a more restricted expression pattern, is more easily up-regulated by mild hypoxia than HIF- $1 \alpha$, and is implicated in maintaining GSCs in an undifferentiated state. ${ }^{68,71}$ Simultaneous expression of HIF-2 $\alpha$ and CA9 negatively correlates with GBM survival. ${ }^{60,64,72}$ shRNA inhibition of HIF- $1 \alpha$ or HIF- $2 \alpha$ reduces GSC neurosphere formation, VEGF production, and EC growth in vitro and prevents tumor formation in orthotopic xenograft GBM models. ${ }^{71}$

\section{GBM-EC Transdifferentiation}

Several groups recently reported that GSCs or stem-like GBM cells possess the ability to transdifferentiate into functional ECs or pericytes that actively participate in constructing GBM vasculature. Ricci-Vitiani et $\mathrm{al}^{73}$ demonstrated that a variable but significant number of $\mathrm{CD} 31^{+} / \mathrm{CD} 144^{+}$GBM ECs possess the same genomic alterations as tumor cells, indicating a significant portion of the vascular endothelium has a neoplastic origin. An alternative explanation of these findings entail exosomal exchange between ECs and GBM cells. ${ }^{74}$ When GBM neurospheres and primary GBM-differentiated cells were cultured under endothelial conditions, only neurospheres enriched in GSCs generated CD31 ${ }^{+}$and tyrosine kinase with Ig and EGF homology domains (Tie) $2^{+}$microvascular cells. Injection of GSCs into immunocompromised mice produced tumor xenografts with vessels composed primarily of human ECs. ${ }^{73}$ Selective targeting of GSC-derived ECs resulted in tumor reduction and degeneration, advocating the functional relevance of GSC-derived endothelial vessels. $^{73}$

Soda et $\mathrm{al}^{75}$ detected tumor-derived ECs (TDECs) in orthotopic GBM glial fibrillary acidic protein-Crep53 $3^{+/-}$ mouse models. Immunofluorescence assays and flow cytometry of the GBM vasculature showed some ECs expressed not only endothelial antigens but also glial fibrillary acidic protein, which most likely originated from tumor cells. ${ }^{75}$ The TDECs, able to form functional vasculature capable of transporting red blood cells, originated from GBM-initiating cells and not from contaminated EC progenitors or from cell-to-cell fusion between tumor cells and ECs. TDECs were also present in a xenograft model of human GBM spheres derived from GBM patients. ${ }^{75}$ TDECs were mostly found in more central hypoxic tumor regions rather than in the periphery, suggesting hypoxia may be a stimulus for TDEC formation. Adding deferoxamine to GBM cell media to mimic hypoxia enhanced HIF- $1 \alpha$ expression, TDEC formation, and formation of tubular structures. AAT led to increased TDECs, suggesting that TDECs contribute to the clinical resistance of GBM to $\mathrm{AAT}^{75}$ BEV treatment inhibited tumor endothelial progenitor differentiation to fully differentiated ECs, but it could not inhibit the differentiation of $\mathrm{CD} 133^{+}$cells into endothelial progenitors. However, Notch-1 silencing blocked early-stage GBM cell differentiation into an EC intermediate precursor, implicating Notch signaling as a possible mechanism for VEGFR2-independent TDEC formation. $^{76}$

The precise role of transdifferentiation in GBMs is an active area of debate, with other groups reporting that vascular ECs do not share genetic similarities with the surrounding GBM cells and that GSCs do not significantly contribute to EC formation. ${ }^{77,78}$ Cheng et al ${ }^{77}$ suggested that GSCs transdifferentiate into Tie-2-expressing pericytes, whose targeting abrogated vessel function and tumor growth.

\section{Vasoformative Responses}

\section{Vasculogenesis}

Bone marrow-derived cells (BMDCs) directly incorporate themselves into forming vessels and are capable of producing proangiogenic factors. Although the exact mechanisms underlying BMDC mobilization, homing to the tumor, and subsequent retention within the tumor are still under investigation, VEGF, placental growth factor, angiopoietin-1, PDGF- $\beta$, and stromal cell-derived factor (SDF)-1 have all been implicated. ${ }^{79}$ Regional hypoxia may induce EC production of angiopoietin-2, Tie-2, CXCL12, PDGF- $\beta$, basic fibroblast growth factor (bFGF), and VEGF, whereas tumor cell production of PDGF- $\beta$ may up-regulate EC SDF-1 production, leading to BMDC migration and proliferation. ${ }^{80}$ 
Murine models demonstrate that SDF-1 secretion induce BMDC differentiation into endothelium and pericytes, the latter existing predominantly in hypoxic areas. ${ }^{81} \mathrm{Du}$ et al ${ }^{82}$ initially observed that wild-type GBM mice contained three times more $\mathrm{CD} 45^{+}$monocytic cells and four times more endothelial precursor cells than their HIF- $1 \alpha \mathrm{KO}$ GBM counterparts. They demonstrated that GBMs recruit $\mathrm{CXCR}^{+}{ }^{+}$BMDCs through a hypoxia-induced HIF- $1 \alpha$-mediated SDF- $1 \alpha$ up-regulation to stimulate neovascularization. ${ }^{82}$

\section{VM}

Vascular mimicry (VM) is the ability to form functional, perfused, vessel-like networks with tumor cells or to patch pre-existing damaged blood vessels with tumor cells. It was first described in human metastatic melanoma models, wherein red blood cells containing vascular networks were constructed without ECs, and the aggressive melanoma cells exhibited up-regulation of angiogenic genes. ${ }^{83}$ Higher incidences of VM have been reported in oxygen-depleted melanoma models and is associated with HIF- $1 \alpha$, VEGF, and MMP expression, providing evidence of a hypoxiadriven mechanism. ${ }^{84}$ One study demonstrated a close association between VM and hypoxic areas in Ewing's sarcoma, implying VM may be a response to inadequate vascularization by normal angiogenic processes. ${ }^{85}$ Although the role of hypoxia in GBM VM has yet to be determined, GBM VM has been associated with aggressive behavior, invasive phenotype, and GBM RT resistance. ${ }^{86}$

\section{Alternate Angiogenic Pathways}

Long-term BEV treatment elicits compensatory proangiogenic pathways, including SDF- $1 \alpha$, bFGF, and Tie- $2 .{ }^{87}$ Microarray analysis of GBM cells treated with BEV revealed up-regulation of angiogenin, IL- $1 \alpha$, acid FGF, bFGF, and transforming growth factor $\alpha .{ }^{87}$ Although initial $\mathrm{BEV}$ treatment reduced vascularity and proliferation, the ensuing up-regulated bFGF expression corresponded with increases in microvessel density and proliferation. ${ }^{88}$

Integrins are a promising antiangiogenic target in GBMs. These cell-adhesion molecules, expressed by TMVECs, possess extracellular matrix modulating and angiogenic properties and are implicated in tumor cell survival, invasion, and migration. ${ }^{89,90}$ GBM grade is associated with $\alpha v \beta 3$ and $\alpha v \beta 5$ integrin expression at the GBM edge, and $\alpha 5$ integrin expression increases after acquired GBM resistance to $\mathrm{AAT}^{29,91}$ Hypoxia induces $\alpha \mathrm{v} \beta 3$ and $\alpha \mathrm{v} \beta 5$ integrin recruitment to the cellular membrane of U87 and SF763 GBM cells by activating FAK. Inhibition of $\alpha v \beta 3, \alpha v \beta 5$, and FAK decreased HIF- $1 \alpha$ and HIF-regulated genes, including VEGF, whereas $\beta 3$ integrin inhibition in U87 xenografts decreased tumor hypoxia, creating thinner, more uniform vessels. ${ }^{92}$

$\beta 1$ Integrin, involved in a plethora of cellular functions ranging from proliferation and adhesion to pathologic functions, including inflammation, invasion, and VEGF- dependent and independent angiogenesis, has also been implicated in AAT resistance. ${ }^{93-95}$ Carbonell et $\mathrm{al}^{96}$ showed patients with BEV-resistant GBMs possessed increased $\beta 1$ integrin and phosphorylated FAK expression, corresponding with increased CA9 staining within hypoxic tumor cores. shRNA-mediated knockdown of $\beta 1$ integrin in mice inoculated with BEV-resistant GBMs reduced tumor growth in a gene-dosage manner. ${ }^{96}$ Combination therapy with full doses of both $\beta 1$ integrin monoclonal antibody and BEV in U87 xenografts was abruptly ended in week three of testing due to rapid tumor ulceration in $100 \%$ of the mice. ${ }^{96}$ However, alternating $\beta 1$ integrin monoclonal antibody and BEV treatments led to tumor regression in $56 \%$ of mice. ${ }^{96}$

\section{Acknowledgments}

We thank Julio Garcia and Elad Mashiach for artwork.

\section{References}

1. Woehrer A, Bauchet L, Barnholtz-Sloan JS: Glioblastoma survival: has it improved? Evidence from population-based studies. Curr Opin Neurol 2014, 27:666-674

2. Wen PY, Kesari S: Malignant gliomas in adults. N Engl J Med 2008, 359:492-507

3. Fischer I, Gagner JP, Law M, Newcomb EW, Zagzag D: Angiogenesis in gliomas: biology and molecular pathophysiology. Brain Pathol 2005, 15:297-310

4. Gilbert MR, Dignam JJ, Armstrong TS, Wefel JS, Blumenthal DT, Vogelbaum MA, Colman H, Chakravarti A, Pugh S, Won M, Jeraj R, Brown PD, Jaeckle KA, Schiff D, Stieber VW, Brachman DG, Werner-Wasik M, Tremont-Lukats IW, Sulman EP, Aldape KD, Curran WJ Jr, Mehta MP: A randomized trial of bevacizumab for newly diagnosed glioblastoma. N Engl J Med 2014, 370:699-708

5. Jain RK, di Tomaso E, Duda DG, Loeffler JS, Sorensen AG, Batchelor TT: Angiogenesis in brain tumours. Nat Rev Neurosci 2007, 8:610-622

6. Kusters B, de Waal RM, Wesseling P, Verrijp K, Maass C, Heerschap A, Barentsz JO, Sweep F, Ruiter DJ, Leenders WP: Differential effects of vascular endothelial growth factor A isoforms in a mouse brain metastasis model of human melanoma. Cancer Res 2003, 63:5408-5413

7. Dubois LG, Campanati L, Righy C, D'Andrea-Meira I, Spohr TC, Porto-Carreiro I, Pereira CM, Balca-Silva J, Kahn SA, DosSantos MF, Oliveira Mde A, Ximenes-da-Silva A, Lopes MC, Faveret E, Gasparetto EL, Moura-Neto V: Gliomas and the vascular fragility of the blood brain barrier. Front Cell Neurosci 2014, 8:418

8. Moens S, Goveia J, Stapor PC, Cantelmo AR, Carmeliet P: The multifaceted activity of VEGF in angiogenesis - implications for therapy responses. Cytokine Growth Factor Rev 2014, 25:473-482

9. Leenders WP, Kusters B, de Waal RM: Vessel co-option: how tumors obtain blood supply in the absence of sprouting angiogenesis. Endothelium 2002, 9:83-87

10. Shibuya M: Vascular endothelial growth factor and its receptor system: physiological functions in angiogenesis and pathological roles in various diseases. J Biochem 2013, 153:13-19

11. Cohen MH, Shen YL, Keegan P, Pazdur R: FDA drug approval summary: bevacizumab (Avastin) as treatment of recurrent glioblastoma multiforme. Oncologist 2009, 14:1131-1138

12. Chinot OL, Wick W, Mason W, Henriksson R, Saran F, Nishikawa R, Carpentier AF, Hoang-Xuan K, Kavan P, Cernea D, Brandes AA, Hilton M, Abrey L, Cloughesy T: Bevacizumab plus radiotherapy- 
temozolomide for newly diagnosed glioblastoma. N Engl J Med 2014, 370:709-722

13. Iwamoto FM, Abrey LE, Beal K, Gutin PH, Rosenblum MK, Reuter VE, DeAngelis LM, Lassman AB: Patterns of relapse and prognosis after bevacizumab failure in recurrent glioblastoma. Neurology 2009, 73:1200-1206

14. Wesseling P, Ruiter DJ, Burger PC: Angiogenesis in brain tumors; pathobiological and clinical aspects. J Neurooncol 1997, 32: 253-265

15. Narayana A, Kunnakkat SD, Medabalmi P, Golfinos J, Parker E, Knopp E, Zagzag D, Eagan P, Gruber D, Gruber ML: Change in pattern of relapse after antiangiogenic therapy in high-grade glioma. Int J Radiat Oncol Biol Phys 2012, 82:77-82

16. Narayana A, Gruber D, Kunnakkat S, Golfinos JG, Parker E, Raza S, Zagzag D, Eagan P, Gruber ML: A clinical trial of bevacizumab, temozolomide, and radiation for newly diagnosed glioblastoma. J Neurosurg 2012, 116:341-345

17. Norden AD, Young GS, Setayesh K, Muzikansky A, Klufas R, Ross GL, Ciampa AS, Ebbeling LG, Levy B, Drappatz J, Kesari S, Wen PY: Bevacizumab for recurrent malignant gliomas: efficacy, toxicity, and patterns of recurrence. Neurology 2008, 70:779-787

18. Narayana A, Kelly P, Golfinos J, Parker E, Johnson G, Knopp E, Zagzag D, Fischer I, Raza S, Medabalmi P, Eagan P, Gruber ML: Antiangiogenic therapy using bevacizumab in recurrent high-grade glioma: impact on local control and patient survival. J Neurosurg 2009, 110:173-180

19. Wick W, Chinot OL, Bendszus M, Mason W, Henriksson R, Saran F, Nishikawa R, Revil C, Kerloeguen Y, Cloughesy T: Evaluation of pseudoprogression rates and tumor progression patterns in a phase III trial of bevacizumab plus radiotherapy/temozolomide for newly diagnosed glioblastoma. Neuro Oncol 2016, 18:1434-1441

20. Keunen O, Johansson M, Oudin A, Sanzey M, Rahim SA, Fack F, Thorsen F, Taxt T, Bartos M, Jirik R, Miletic H, Wang J, Stieber D, Stuhr L, Moen I, Rygh CB, Bjerkvig R, Niclou SP: Anti-VEGF treatment reduces blood supply and increases tumor cell invasion in glioblastoma. Proc Natl Acad Sci U S A 2011, 108:3749-3754

21. Hamans B, Navis AC, Wright A, Wesseling P, Heerschap A, Leenders W: Multivoxel (1)H MR spectroscopy is superior to contrast-enhanced MRI for response assessment after anti-angiogenic treatment of orthotopic human glioma xenografts and provides handles for metabolic targeting. Neuro Oncol 2013, 15:1615-1624

22. Jain RK: Normalization of tumor vasculature: an emerging concept in antiangiogenic therapy. Science 2005, 307:58-62

23. de Groot JF, Fuller G, Kumar AJ, Piao Y, Eterovic K, Ji Y, Conrad CA: Tumor invasion after treatment of glioblastoma with bevacizumab: radiographic and pathologic correlation in humans and mice. Neuro Oncol 2010, 12:233-242

24. Kumar K, Wigfield S, Gee HE, Devlin CM, Singleton D, Li JL, Buffa F, Huffman M, Sinn AL, Silver J, Turley H, Leek R, Harris AL, Ivan M: Dichloroacetate reverses the hypoxic adaptation to bevacizumab and enhances its antitumor effects in mouse xenografts. J Mol Med (Berl) 2013, 91:749-758

25. Rapisarda A, Hollingshead M, Uranchimeg B, Bonomi CA, Borgel SD, Carter JP, Gehrs B, Raffeld M, Kinders RJ, Parchment R, Anver MR, Shoemaker RH, Melillo G: Increased antitumor activity of bevacizumab in combination with hypoxia inducible factor-1 inhibition. Mol Cancer Ther 2009, 8:1867-1877

26. Yang L, Lin C, Wang L, Guo H, Wang X: Hypoxia and hypoxiainducible factors in glioblastoma multiforme progression and therapeutic implications. Exp Cell Res 2012, 318:2417-2426

27. Hill RP, Bristow RG, Fyles A, Koritzinsky M, Milosevic M, Wouters BG: Hypoxia and predicting radiation response. Semin Radiat Oncol 2015, 25:260-272

28. Bristow RG, Hill RP: Hypoxia and metabolism. Hypoxia, DNA repair and genetic instability. Nat Rev Cancer 2008, 8:180-192

29. DeLay M, Jahangiri A, Carbonell WS, Hu YL, Tsao S, Tom MW, Paquette J, Tokuyasu TA, Aghi MK: Microarray analysis verifies two distinct phenotypes of glioblastomas resistant to antiangiogenic therapy. Clin Cancer Res 2012, 18:2930-2942

30. Chen Q, Jin M, Yang F, Zhu J, Xiao Q, Zhang L: Matrix metalloproteinases: inflammatory regulators of cell behaviors in vascular formation and remodeling. Mediators Inflamm 2013, 2013:928315

31. Garcia-Navarrete R, Garcia E, Arrieta O, Sotelo J: Hepatocyte growth factor in cerebrospinal fluid is associated with mortality and recurrence of glioblastoma, and could be of prognostic value. J Neurooncol 2010, 97:347-351

32. Hu B, Guo P, Bar-Joseph I, Imanishi Y, Jarzynka MJ, Bogler O, Mikkelsen T, Hirose T, Nishikawa R, Cheng SY: Neuropilin-1 promotes human glioma progression through potentiating the activity of the HGF/SF autocrine pathway. Oncogene 2007, 26: $5577-5586$

33. Rose SD, Aghi MK: Mechanisms of evasion to antiangiogenic therapy in glioblastoma. Clin Neurosurg 2010, 57:123-128

34. Navis AC, Bourgonje A, Wesseling P, Wright A, Hendriks W, Verrijp K, van der Laak JA, Heerschap A, Leenders WP: Effects of dual targeting of tumor cells and stroma in human glioblastoma xenografts with a tyrosine kinase inhibitor against c-MET and VEGFR2. PLoS One 2013, 8:e58262

35. Jahangiri A, De Lay M, Miller LM, Carbonell WS, Hu YL, Lu K, Tom MW, Paquette J, Tokuyasu TA, Tsao S, Marshall R, Perry A, Bjorgan KM, Chaumeil MM, Ronen SM, Bergers G, Aghi MK: Gene expression profile identifies tyrosine kinase c-Met as a targetable mediator of antiangiogenic therapy resistance. Clin Cancer Res 2013, 19:1773-1783

36. Lu KV, Chang JP, Parachoniak CA, Pandika MM, Aghi MK, Meyronet D, Isachenko N, Fouse SD, Phillips JJ, Cheresh DA, Park M, Bergers G: VEGF inhibits tumor cell invasion and mesenchymal transition through a MET/VEGFR2 complex. Cancer Cell 2012, 22:21-35

37. Wen PY, Schiff D, Cloughesy TF, Raizer JJ, Laterra J, Smitt M, Wolf M, Oliner KS, Anderson A, Zhu M, Loh E, Reardon DA: A phase II study evaluating the efficacy and safety of AMG 102 (rilotumumab) in patients with recurrent glioblastoma. Neuro Oncol 2011, $13: 437-446$

38. Vartanian A, Singh SK, Agnihotri S, Jalali S, Burrell K, Aldape KD, Zadeh G: GBM's multifaceted landscape: highlighting regional and microenvironmental heterogeneity. Neuro Oncol 2014, 16: $1167-1175$

39. Semenza GL: HIF-1 mediates metabolic responses to intratumoral hypoxia and oncogenic mutations. J Clin Invest 2013, 123: 3664-3671

40. Marie SK, Shinjo SM: Metabolism and brain cancer. Clinics (Sao Paulo) 2011, 66(Suppl 1):33-43

41. Michelakis ED, Sutendra G, Dromparis P, Webster L, Haromy A, Niven E, Maguire C, Gammer TL, Mackey JR, Fulton D, Abdulkarim B, McMurtry MS, Petruk KC: Metabolic modulation of glioblastoma with dichloroacetate. Sci Transl Med 2010, 2:31ra4

42. Ward PS, Thompson CB: Metabolic reprogramming: a cancer hallmark even warburg did not anticipate. Cancer Cell 2012, 21:297-308

43. Granchi C, Fancelli D, Minutolo F: An update on therapeutic opportunities offered by cancer glycolytic metabolism. Bioorg Med Chem Lett 2014, 24:4915-4925

44. Galeffi F, Turner DA: Exploiting metabolic differences in glioma therapy. Curr Drug Discov Technol 2012, 9:280-293

45. Sonveaux P, Vegran F, Schroeder T, Wergin MC, Verrax J, Rabbani ZN, De Saedeleer CJ, Kennedy KM, Diepart C, Jordan BF, Kelley MJ, Gallez B, Wahl ML, Feron O, Dewhirst MW: Targeting lactate-fueled respiration selectively kills hypoxic tumor cells in mice. J Clin Invest 2008, 118:3930-3942

46. Poteet E, Choudhury GR, Winters A, Li W, Ryou MG, Liu R, Tang L, Ghorpade A, Wen Y, Yuan F, Keir ST, Yan H, Bigner DD, Simpkins JW, Yang SH: Reversing the Warburg effect as a treatment for glioblastoma. J Biol Chem 2013, 288:9153-9164 
47. Velpula KK, Bhasin A, Asuthkar S, Tsung AJ: Combined targeting of PDK1 and EGFR triggers regression of glioblastoma by reversing the Warburg effect. Cancer Res 2013, 73:7277-7289

48. Nanegrungsunk D, Onchan W, Chattipakorn N, Chattipakorn SC: Current evidence of temozolomide and bevacizumab in treatment of gliomas. Neurol Res 2015, 37:167-183

49. Levine B, Klionsky DJ: Development by self-digestion: molecular mechanisms and biological functions of autophagy. Dev Cell 2004, 6: 463-477

50. Mazure NM, Pouyssegur J: Hypoxia-induced autophagy: cell death or cell survival? Curr Opin Cell Biol 2010, 22:177-180

51. Hait WN, Jin S, Yang JM: A matter of life or death (or both): understanding autophagy in cancer. Clin Cancer Res 2006, 12: 1961-1965

52. Bacon AL, Harris AL: Hypoxia-inducible factors and hypoxic cell death in tumour physiology. Ann Med 2004, 36:530-539

53. Kothari S, Cizeau J, McMillan-Ward E, Israels SJ, Bailes M, Ens K, Kirshenbaum LA, Gibson SB: BNIP3 plays a role in hypoxic cell death in human epithelial cells that is inhibited by growth factors EGF and IGF. Oncogene 2003, 22:4734-4744

54. Lefranc F, Kiss R: Autophagy, the Trojan horse to combat glioblastomas. Neurosurg Focus 2006, 20:E7

55. Kanzawa T, Zhang L, Xiao L, Germano IM, Kondo Y, Kondo S: Arsenic trioxide induces autophagic cell death in malignant glioma cells by upregulation of mitochondrial cell death protein BNIP3. Oncogene 2005, 24:980-991

56. Daido S, Kanzawa T, Yamamoto A, Takeuchi H, Kondo Y, Kondo S: Pivotal role of the cell death factor BNIP3 in ceramide-induced autophagic cell death in malignant glioma cells. Cancer Res 2004, 64:4286-4293

57. Azad MB, Chen Y, Henson ES, Cizeau J, McMillan-Ward E, Israels SJ, Gibson SB: Hypoxia induces autophagic cell death in apoptosis-competent cells through a mechanism involving BNIP3. Autophagy 2008, 4:195-204

58. Chen Y, Meng D, Wang H, Sun R, Wang D, Wang S, Fan J, Zhao Y, Wang J, Yang S, Huai C, Song X, Qin R, Xu T, Yun D, Hu L, Yang J, Zhang X, Chen H, Chen J, Chen H, Lu D: VAMP8 facilitates cellular proliferation and temozolomide resistance in human glioma cells. Neuro Oncol 2015, 17:407-418

59. Palumbo S, Pirtoli L, Tini P, Cevenini G, Calderaro F, Toscano M, Miracco C, Comincini S: Different involvement of autophagy in human malignant glioma cell lines undergoing irradiation and temozolomide combined treatments. J Cell Biochem 2012, 113: 2308-2318

60. Bao S, Wu Q, Sathornsumetee S, Hao Y, Li Z, Hjelmeland AB, Shi Q, McLendon RE, Bigner DD, Rich JN: Stem cell-like glioma cells promote tumor angiogenesis through vascular endothelial growth factor. Cancer Res 2006, 66:7843-7848

61. Liebelt BD, Shingu T, Zhou X, Ren J, Shin SA, Hu J: Glioma stem cells: signaling, microenvironment, and therapy. Stem Cells Int 2016, 2016:7849890

62. Gilbertson RJ, Rich JN: Making a tumour's bed: glioblastoma stem cells and the vascular niche. Nat Rev Cancer 2007, 7: 733-736

63. Gupta T, Nair V, Jalali R: Stem cell niche irradiation in glioblastoma: providing a ray of hope? CNS Oncol 2014, 3:367-376

64. Heddleston JM, Li Z, McLendon RE, Hjelmeland AB, Rich JN: The hypoxic microenvironment maintains glioblastoma stem cells and promotes reprogramming towards a cancer stem cell phenotype. Cell Cycle 2009, 8:3274-3284

65. Pistollato F, Abbadi S, Rampazzo E, Persano L, Della Puppa A, Frasson C, Sarto E, Scienza R, D'Avella D, Basso G: Intratumoral hypoxic gradient drives stem cells distribution and MGMT expression in glioblastoma. Stem Cells 2010, 28:851-862

66. Platet N, Liu SY, Atifi ME, Oliver L, Vallette FM, Berger F, Wion D: Influence of oxygen tension on CD133 phenotype in human glioma cell cultures. Cancer Lett 2007, 258:286-290
67. Bar EE, Lin A, Mahairaki V, Matsui W, Eberhart CG: Hypoxia increases the expression of stem-cell markers and promotes clonogenicity in glioblastoma neurospheres. Am J Pathol 2010, 177: $1491-1502$

68. McCord AM, Jamal M, Shankavaram UT, Lang FF, Camphausen K, Tofilon PJ: Physiologic oxygen concentration enhances the stem-like properties of CD133+ human glioblastoma cells in vitro. Mol Cancer Res 2009, 7:489-497

69. Mao XG, Yan M, Xue XY, Zhang X, Ren HG, Guo G, Wang P, Zhang W, Huo JL: Overexpression of ZNF217 in glioblastoma contributes to the maintenance of glioma stem cells regulated by hypoxia-inducible factors. Lab Invest 2011, 91:1068-1078

70. Kolenda J, Jensen SS, Aaberg-Jessen C, Christensen K, Andersen C, Brunner N, Kristensen BW: Effects of hypoxia on expression of a panel of stem cell and chemoresistance markers in glioblastomaderived spheroids. J Neurooncol 2011, 103:43-58

71. Li Z, Bao S, Wu Q, Wang H, Eyler C, Sathornsumetee S, Shi Q, Cao Y, Lathia J, McLendon RE, Hjelmeland AB, Rich JN: Hypoxiainducible factors regulate tumorigenic capacity of glioma stem cells. Cancer Cell 2009, 15:501-513

72. Sathornsumetee S, Cao Y, Marcello JE, Herndon JE II, McLendon RE, Desjardins A, Friedman HS, Dewhirst MW, Vredenburgh JJ, Rich JN: Tumor angiogenic and hypoxic profiles predict radiographic response and survival in malignant astrocytoma patients treated with bevacizumab and irinotecan. J Clin Oncol 2008, 26:271-278

73. Ricci-Vitiani L, Pallini R, Biffoni M, Todaro M, Invernici G, Cenci T, Maira G, Parati EA, Stassi G, Larocca LM, De Maria R: Tumour vascularization via endothelial differentiation of glioblastoma stem-like cells. Nature 2010, 468:824-828

74. Zhang X, Yuan X, Shi H, Wu L, Qian H, Xu W: Exosomes in cancer: small particle, big player. J Hematol Oncol 2015, 8:83

75. Soda Y, Marumoto T, Friedmann-Morvinski D, Soda M, Liu F, Michiue H, Pastorino S, Yang M, Hoffman RM, Kesari S, Verma IM: Transdifferentiation of glioblastoma cells into vascular endothelial cells. Proc Natl Acad Sci U S A 2011, 108:4274-4280

76. Wang R, Chadalavada K, Wilshire J, Kowalik U, Hovinga KE, Geber A, Fligelman B, Leversha M, Brennan C, Tabar V: Glioblastoma stem-like cells give rise to tumour endothelium. Nature 2010, 468:829-833

77. Cheng L, Huang Z, Zhou W, Wu Q, Donnola S, Liu JK, Fang X, Sloan AE, Mao Y, Lathia JD, Min W, McLendon RE, Rich JN, Bao S: Glioblastoma stem cells generate vascular pericytes to support vessel function and tumor growth. Cell 2013, 153:139-152

78. Rodriguez FJ, Orr BA, Ligon KL, Eberhart CG: Neoplastic cells are a rare component in human glioblastoma microvasculature. Oncotarget 2012, 3:98-106

79. Semenza GL: Cancer-stromal cell interactions mediated by hypoxiainducible factors promote angiogenesis, lymphangiogenesis, and metastasis. Oncogene 2013, 32:4057-4063

80. Boer JC, Walenkamp AM, den Dunnen WF: Recruitment of bone marrow derived cells during anti-angiogenic therapy in GBM: the potential of combination strategies. Crit Rev Oncol Hematol 2014, 92:38-48

81. Aghi M, Cohen KS, Klein RJ, Scadden DT, Chiocca EA: Tumor stromal-derived factor-1 recruits vascular progenitors to mitotic neovasculature, where microenvironment influences their differentiated phenotypes. Cancer Res 2006, 66:9054-9064

82. Du R, Lu KV, Petritsch C, Liu P, Ganss R, Passegue E, Song H, Vandenberg S, Johnson RS, Werb Z, Bergers G: HIF1alpha induces the recruitment of bone marrow-derived vascular modulatory cells to regulate tumor angiogenesis and invasion. Cancer Cell 2008, 13: 206-220

83. Demou ZN, Hendrix MJ: Microgenomics profile the endogenous angiogenic phenotype in subpopulations of aggressive melanoma. J Cell Biochem 2008, 105:562-573

84. Sun B, Zhang D, Zhang S, Zhang W, Guo H, Zhao X: Hypoxia influences vasculogenic mimicry channel formation and tumor 
invasion-related protein expression in melanoma. Cancer Lett 2007, 249:188-197

85. van der Schaft DW, Hillen F, Pauwels P, Kirschmann DA, Castermans K, Egbrink MG, Tran MG, Sciot R, Hauben E, Hogendoorn PC, Delattre O, Maxwell PH, Hendrix MJ, Griffioen AW: Tumor cell plasticity in Ewing sarcoma, an alternative circulatory system stimulated by hypoxia. Cancer Res 2005, 65:11520-11528

86. Hardee ME, Zagzag D: Mechanisms of glioma-associated neovascularization. Am J Pathol 2012, 181:1126-1141

87. Ebos JM, Kerbel RS: Antiangiogenic therapy: impact on invasion, disease progression, and metastasis. Nat Rev Clin Oncol 2011, 8:210-221

88. Lucio-Eterovic AK, Piao Y, de Groot JF: Mediators of glioblastoma resistance and invasion during antivascular endothelial growth factor therapy. Clin Cancer Res 2009, 15:4589-4599

89. Tchaicha JH, Reyes SB, Shin J, Hossain MG, Lang FF, McCarty JH: Glioblastoma angiogenesis and tumor cell invasiveness are differentially regulated by beta8 integrin. Cancer Res 2011, 71:6371-6381

90. Seguin L, Desgrosellier JS, Weis SM, Cheresh DA: Integrins and cancer: regulators of cancer stemness, metastasis, and drug resistance. Trends Cell Biol 2015, 25:234-240
91. Bello L, Francolini M, Marthyn P, Zhang J, Carroll RS, Nikas DC, Strasser JF, Villani R, Cheresh DA, Black PM: Alpha(v)beta3 and alpha(v)beta5 integrin expression in glioma periphery. Neurosurgery 2001, 49:380-389. discussion 90

92. Skuli N, Monferran S, Delmas C, Favre G, Bonnet J, Toulas C, Cohen-Jonathan Moyal E: Alphavbeta3/alphavbeta5 integrins-FAKRhoB: a novel pathway for hypoxia regulation in glioblastoma. Cancer Res 2009, 69:3308-3316

93. Cordes N, Park CC: beta1 integrin as a molecular therapeutic target. Int J Radiat Biol 2007, 83:753-760

94. Desgrosellier JS, Cheresh DA: Integrins in cancer: biological implications and therapeutic opportunities. Nat Rev Cancer 2010, 10:9-22

95. Leenders WP, Kusters B, Verrijp K, Maass C, Wesseling P, Heerschap A, Ruiter D, Ryan A, de Waal R: Antiangiogenic therapy of cerebral melanoma metastases results in sustained tumor progression via vessel co-option. Clin Cancer Res 2004, 10:6222-6230

96. Carbonell WS, DeLay M, Jahangiri A, Park CC, Aghi MK: beta1 integrin targeting potentiates antiangiogenic therapy and inhibits the growth of bevacizumab-resistant glioblastoma. Cancer Res 2013, 73: $3145-3154$ 